\title{
O conhecimento do teste de triagem neonatal por parte da gestante durante 0 atendimento pré-natal
}

\section{The knowledge of the neonatal screening test by pregnant women during prenatal care}

Adauto Dutra Moraes Barbosa

Professor-Titular de Pediatria da Faculdade de Medicina da Universidade Federal Fluminense.

O atendimento pré-natal à gestante, tanto de alto quanto de baixo risco, é, sem dúvida, um dos principais fatores que contribuem para o sucesso da gravidez e do parto.

Embora durante a gestação o obstetra detecte, conduza e trate possíveis intercorrências que venham a surgir com a grávida, na maioria das vezes, os cuidados relacionados ao futuro nascituro não parecem ser interpretados por ele como sendo uma oportunidade ímpar de alertar sobre condutas neonatais importantes já estabelecidas, entre elas a necessidade de se realizar os testes de triagem neonatal nos primeiros dias após o nascimento e o que estes significam para a criança.

Publicações recentes ${ }^{1,2,3}$ mostram que a dificuldade da gestante em tomar conhecimento da importância e de 'para que serve' o teste - popularmente chamado 'teste do pezinho' - parece um desafio a ser vencido na era da informação. Publicações acerca da questão convergem para o mesmo ponto, ou seja, falta de intervenção educacional precoce visando instruir os pais.

A capacitação do pessoal da área de saúde, em especial da enfermagem, ${ }^{4}$ tem sido a grande iniciativa para que se consiga maior adesão ao programa de triagem neonatal. Por outro lado, não é do nosso conhecimento, baseado em pesquisa bibliográfica, o efetivo apoio pré-natal por parte do obstetra, na incorporação dessa matéria durante o cuidado pré-natal.

Neste número da Revista de Pediatria SOPERJ, Guimarães et al., analisando os fatores envolvidos na falta de conhecimento materno sobre os testes de triagem neonatal, incluíram um dado preocupante ao verificar que nas maternidades de alta complexidade o desconhecimento sobre o assunto é maior. Assim, pode-se inferir que as equipes que atendem a essas gestantes voltam-se ordinariamente para os problemas circunstanciais do alto risco, dissociando-os da possível morbidade, que pode ter seu diagnóstico ao alcance de um screening test.

Dessa forma, enfatizamos a necessidade de se alertar os profissionais consultados no período pré-natal, que também são responsáveis pela orientação e esclarecimentos acerca dos testes de triagem neonatal a serem realizados, esclarecendo sua importância e vantagens para o recém-nascido.

\section{REFERÊNCIAS}

1 Oliveira JG, Sandrini D, Costa DC, Serradilha AFZ, Parro MC. Triagem neonatal ou teste do pezinho: conhecimento, orientações e importância para a saúde do recém-nascido. CuidArte, Enferm. 2008;2(1):71-6.

2 Silva MPC, Contim D, Ferreira LA, Marqui ABT. Teste do pezinho: percepção das gestantes nas orientações no prénatal. Rev Bras Saúde Matern Infant. 2017;17(2):299-305.

3 Arduini GAO, Balarin MAS, SilvaGrecco RL, Marqui ABT. Conhecimento das puérperas sobre o teste do pezinho. Rev Paul Pediatr. 2017;35(2):151-7.

4 Strefling ISS, Monfrim XM, Lunardi Filho WD, Carvalho KK, Azevedo ALS. Conhecimento sobre triagem neonatal e sua operacionalização. Cogitare Enferm. 2014;19(1):27-33. 